\title{
Biological Control Agents for Fire Blight of Apple Compared Under Conditions Limiting Natural Dispersal
}

\author{
P. L. Pusey, USDA-ARS, Tree Fruit Research Laboratory, 1104 N. Western Ave., Wenatchee, WA 98801
}

\begin{abstract}
Pusey, P. L. 2002. Biological control agents for fire blight of apple compared under conditions limiting natural dispersal. Plant Dis. 86:639-644.

The efficacy of Pantoea agglomerans strain E325 for control of fire blight of apple was determined in comparative field trials involving other bacterial antagonists. Concurrently, the importance of the natural dispersal of bacteria as a complicating factor was assessed. Tests were performed under two sets of conditions, those that allowed for the dispersal of bacteria via honeybee activity and those that minimized it through the use of translucent polyethylene enclosures around single trees. The enclosures also raised daytime temperatures and allowed for controlled wetting, two factors important to the development of blossom blight. Singleantagonist treatments with strain E325, Pseudomonas fluorescens strain A506, and P. agglomerans strain C9-1 were applied to open blossoms on each of 10 enclosed trees and 10 nonenclosed trees. During bloom, suspensions of antagonists $\left(10^{8} \mathrm{CFU} / \mathrm{ml}\right)$ were applied twice with a brush, and a suspension of Erwinia amylovora $\left(10^{7} \mathrm{CFU} / \mathrm{ml}\right)$ was subsequently applied once using the same method. Two days after inoculation with the pathogen, trees were misted to simulate precipitation. Flower-to-flower spread of antagonistic bacteria was less frequent on trees surrounded by plastic enclosures than on nonenclosed trees. The range and statistical separation of means for population size of E. amylovora and disease incidence among treatments were greater for enclosed trees than for nonenclosed trees. Based on these results, the natural spread of antagonists being compared may mask differences in their efficacy as biocontrol agents. Such distortions and resulting misinterpretations could be lessened by separating treatments widely in large orchard blocks and by monitoring microbial populations. Strain E325 from fresh or lyophilized cultures was consistently more effective than standard antagonists in suppressing E. amylovora and reducing disease incidence. To fully assess its potential use for fire blight, larger-scale trials under various conditions will be necessary.
\end{abstract}

Fire blight, which is a major constraint to pome fruit production in many areas of the world, is most commonly initiated by epiphytic populations of Erwinia amylovora that develop on blossoms $(1,26)$. Under relatively dry climatic conditions, bacteria colonize flower stigmas, and subsequent rain or heavy dew facilitates movement to the floral cup (hypanthium), where infection generally occurs (24). Management programs in the United States have focused on suppressing E. amylovora on floral parts using antibiotics, and disease control has been especially dependent on the use of streptomycin; however, pathogen resistance to this antibiotic has developed in many production areas $(13,14)$.

Suppression of the blossom blight phase of fire blight with microbial antagonists has been widely demonstrated as an alternative $(4,8)$ or complementary measure

Corresponding author: P. L. Pusey

E-mail: pusey@tfrl.ars.usda.gov

Accepted for publication 5 February 2002.

Publication no. D-2002-0325-04R

This article is in the public domain and not copyrightable. It may be freely reprinted with customary crediting of the source. The American Phytopathological Society, 2002.
$(12,22)$ to the use of antibiotics. Pseudomonas fluorescens strain A506, the active ingredient in BlightBan A506 (J. R. Simplot Co., Boise, ID), was originally selected based on its inhibition of an icenucleating strain of Pseudomonas syringae on corn leaves, then later found to reduce fire blight incidence (12). Another bacterial antagonist of commercial interest, Pantoea agglomerans (syn. Erwinia herbicola) strain C9-1 (8), was selected based on in vitro production of antibiotics inhibitory to E. amylovora (7). Other microorganisms reported as potential biological control agents for fire blight, including many strains of $P$. agglomerans, were first discovered in screening assays on artificial media $(2,26)$ or immature pear fruit $(3,5,29)$. Laboratory screening assays on detached crabapple flowers led to our recent discovery of $P$. agglomerans strain E325, which was significantly more effective than other test organisms in suppressing populations of E. amylovora on flower stigmas $(17,19,20)$.

The effects of bacterial antagonists on blossom blight in field trials often have been inconsistent $(4,27)$, perhaps because of environmental factors and the instability or small size of established populations. Another factor that complicates field experiments is the natural dispersal of antagonists following treatment applications.
Bacterial antagonists have been shown to spread from blossom to blossom and tree to tree $(8,16)$, and honeybees have been implicated as the primary vector $(8,9,25,27)$. The capacity of biocontrol agents to be vectored in this way and to colonize plant surfaces away from treated sites is one advantage they have over antibiotics, which protect only the contact area. However, we can reasonably assume that, to some extent, such spread interferes with evaluating and comparing different biocontrol treatments in the same experimental orchard. It may distort the comparison among treatments and the comparison between each treatment and the untreated control.

A field study was conducted to compare the efficacy of P. agglomerans strain E325 with that of other antagonistic strains in reducing fire blight incidence and to simultaneously assess the importance of bacterial dispersal as a complicating factor. This was done under two sets of conditions, one that allowed for honeybee dispersal of bacteria and one that minimized it. Preliminary results of this study were previously reported (20).

\section{MATERIALS AND METHODS}

Microorganisms. $P$. agglomerans strain E325 was isolated originally from 'Gala' apple blossoms near Wenatchee, WA, in 1994 (17). Standard antagonistic strains marked with rifampicin resistance were $P$. agglomerans strain C9-1 and Pseudomonas fluorescens strain A506. The pathogen strain was a nalidixic acid-resistant derivative of E. amylovora strain Ea153. Original strain codes, without letters previously added to indicate specific derivative types, are used in this report. Strain C9-1, originally from C. Ishimaru (Colorado State University, Fort Collins), was isolated from 'Jonathan' apple fruit in Michigan (7), and the rifampicin-resistant derivative was later combined with strain A506 to reduce fire blight of pear (10). Strain A506, originally from S. Lindow (University of California, Berkeley), was isolated from pear in California and reduced the incidence of fire blight $(10,12,28)$. Strain Ea153, obtained from K. Johnson (Oregon State University, Corvallis), was isolated from cankers on 'Gala' apple in Oregon and later used in field biocontrol studies $(9,10,22)$.

Bacteria were cultured on nutrient yeast dextrose agar (NYDA; nutrient broth, $8 \mathrm{~g}$; yeast, $5 \mathrm{~g}$; dextrose, $5 \mathrm{~g}$; agar, $15 \mathrm{~g}$; and deionized water, 1 liter) for $24 \mathrm{~h}$ at $24^{\circ} \mathrm{C}$, 
and inoculum suspensions were prepared in $10 \mathrm{mM}$ potassium phosphate buffer $(\mathrm{pH}$ 7.0) and $0.03 \%$ Tween 20 . In addition to field treatments with strains E325, C9-1, and A506 prepared from fresh laboratory cultures, another treatment was made with strain E325 prepared from a lyophilized form.

Orchard trees and enclosures. In each of 2 years, an apple orchard block was selected based on availability and number of flower clusters. Trees used were 9-yearold 'Jonagold' scion on M7 rootstock in 1997 and 4-year-old 'Gala' scion on M26 rootstock in 1998. Individual apple trees were enclosed in an aluminum frame covered with translucent polyethylene of 0.15$\mathrm{mm}$ thickness. Each enclosure was $3.0 \mathrm{~m}$ wide, $2.4 \mathrm{~m}$ long, and $3.7 \mathrm{~m}$ high. In each year, 10 enclosed and 10 nonenclosed trees in the same experimental block were used.

Inoculation and pollination of blossoms. Antagonists were suspended in buffer at $10^{8} \mathrm{CFU} / \mathrm{ml}$ and applied to open flowers on each tree when trees were at 35 to $40 \%$ bloom and again at 90 to $100 \%$ bloom. Application was made with an artist paint brush by lightly touching the stigmas of each flower. After the second application, the remaining unopened flowers on treated branches were removed. $E$. amylovora strain Ea153 was suspended at $10^{7} \mathrm{CFU} / \mathrm{ml}$ and applied with a brush, as described for antagonists, to all antagonisttreated flowers and to untreated control flowers when trees were at the early petal fall stage. Bacteria were applied tree by tree on each date, between 9:00 A.M. and 4:00 P.M., and inoculation of all trees required 4 to $6 \mathrm{~h}$.

Since bees were not present as pollinators, dry pollen was artificially applied with a brush. In 1997, because it was unknown whether pollination is necessary to obtain reliable data, 5 of the 10 enclosed trees were pollinated 1 day after inoculation with Ea153, and the other five trees were not pollinated. Flowers on all enclosed trees were pollinated twice in 1998, 1 day after the first application of antagonists and 1 day after the second application. Pollen was obtained from a commercial supplier (Firmyield Pollen and Orchard Supply, Wapato, WA) and consisted of a 1:1 mix of 'Braeburn' and 'Red Delicious' apple pollen in 1997, and 'Rome Beauty' and 'Red Delicious' in 1998.

Simulated wetting and weather data. In 1997, 3 days after inoculation with Ea153, trees were subjected to an 11-h period of wetness by repeatedly misting trees with a low-pressure handgun sprayer. In 1998, 2 days after inoculation with Ea153, tree wetness was maintained for an 8-h period with an automatic overhead misting system that was on for 15 min each hour. Temperature, relative humidity, vegetative wetness, and rainfall were monitored inside one or two enclosures and at one nonenclosed site within the orchard block.
Bacterial population size and disease incidence. Immediately prior to wetting trees, and again 2 days after wetting, two flowers per treatment from each tree were sampled to determine bacterial population sizes on flower stigmas and hypanthia. Stigmas of each flower along with portions of the supporting styles were collected and placed in a sterile microcentrifuge tube containing $1 \mathrm{ml}$ of sterile buffer $(10 \mathrm{mM}$ potassium phosphate, $\mathrm{pH}$ 7.0). After the corolla, calyx, and pedicel were removed and discarded, the remaining hypanthium was placed in a separate microcentrifuge tube with buffer. The tubes were vortexed briefly and placed in a sonication bath for 60 s. Samples were again vortexed, and serial dilutions were spread on CCT medium (sucrose, $100 \mathrm{~g}$; sorbitol, $10 \mathrm{~g}$; $1 \%$ aqueous solution of tergitol anionic 7, 30 $\mathrm{ml} ; 0.1 \%$ crystal violet in absolute ethanol, $2 \mathrm{ml}$; nutrient agar, $23 \mathrm{~g}$; and deionized water, $970 \mathrm{ml}$ [6]) amended with nalidixic acid $(100 \mu \mathrm{g} / \mathrm{ml})$, King's B medium (11) amended with rifampicin $(25 \mu \mathrm{g} / \mathrm{ml})$ and cycloheximide $(50 \mu \mathrm{g} / \mathrm{ml})$, and NYDA amended with cycloheximide $(50 \mu \mathrm{g} / \mathrm{ml})$. After 3 or 4 days of incubation at $24^{\circ} \mathrm{C}$, bacterial colonies were counted. The pathogen Ea153 was detected on CCT medium amended with nalidixic acid. Standard antagonists A506 and C9-1 grew on rifampicin-amended King's B medium and were distinguished based on colony characteristics. Strain E325 grew on NYDA, and its population size was based on the number of colonies on NYDA minus the number of C9-1 colonies appearing on rifampicin-amended King's B medium.

Trees were evaluated weekly for the incidence of infected blossom clusters, which were removed promptly upon discovery. Final disease incidence was evaluated 53 days after inoculation in 1997 and 16 days after inoculation in 1998. The experiment was terminated earlier the second year because fire blight progressed more rapidly.

Experimental design and data analysis. On each tree, each treatment was represented by one replicate group of flower clusters (average of 31 in 1997 and 60 in 1998) in close proximity and supported on one or more branches. Frequency of strains A506 and C9-1 detected on untreated control flowers and on flowers not treated with these strains was evaluated by SAS (Version 8.0, SAS Institute, Cary, NC) Fisher's two-sided exact test. Estimated population size of bacterial strains on sampled flowers previously inoculated with the same strains was $\log$-transformed, and values for two flowers per treatment per tree were averaged prior to statistical analysis. Disease incidence was expressed as percentage of treated blossom clusters that became infected. Data for population size and disease incidence were analyzed using SAS analysis of variance (ANOVA), and means were separated according to the least significant difference test $(P \leq 0.05)$. Separate analyses were performed for years 1997 and 1998, enclosed and nonenclosed trees, and pre- and post-wetting bacterial populations.

\section{RESULTS}

Dates when antagonistic and pathogenic bacteria were applied and wetting administered are presented in relation to bloom stage, temperature, and relative humidity (Fig. 1). Inside the tree enclosures, maximum daytime temperatures were 10 to $15^{\circ} \mathrm{C}$ higher than those on the outside (Fig $1 \mathrm{~A}$ and $\mathrm{B})$. Relative humidity in the enclosures was only slightly higher than that on the outside (Fig. 1C and D). Only trace amounts of precipitation were measured outside the enclosures. Vegetative wetness was minimal and never at $100 \%$ on enclosed or nonenclosed trees at any time, except during artificial wetting.

To assess dispersal of bacterial antagonists, frequency and population size of strains A506 and C9-1 were determined for flower stigmas sampled from all treatments on all trees immediately before the wetting period. In both 1997 and 1998, the frequency of A506 and C9-1 on flowers not treated with these strains was consistently higher numerically on nonenclosed trees than on enclosed trees when compared within each treatment, and differences were significant in several cases according to Fisher's two-sided exact test (Table 1). When data from different bacterial treatments were pooled, the difference between frequency of either A506 or C9-1 on enclosed and nonenclosed trees was highly significant $(P<0.001)$. Strain $C 9-1$ was detectable on $95 \%$ of control flowers sampled from nonenclosed trees, but only on $15 \%$ of flowers from enclosed trees. Standard strains contaminated 35 to $75 \%$ of flowers treated with strain E325 on nonenclosed trees, but only 0 to $35 \%$ on enclosed trees. Only flowers with detectable populations of A506 or C9-1 were used to calculate mean population size (Table 1). Although frequency of spread in the two environments appeared different, populations of dispersed antagonists on flowers of enclosed and nonenclosed trees were often of comparable size.

On enclosed trees, the population size of bacterial antagonists was determined for both stigmas and hypanthia before and after the wetting period. A comparison of antagonist populations representing the treatments revealed few differences prior to wetting (Fig. 2). The only statistically significant difference before wetting was in 1998 when the population of strain A506 on flower stigmas was larger than that of strain C9-1 (Fig. 2B). Stigmatic populations before and after wetting in 1997 all exceeded 6 log CFU per flower; in 1998, some means were below this level, particularly after wetting. The size of stigmatic populations of strains C9-1 and E325 of $P$. agglomerans after wetting did not differ 
from each other, but in some cases was greater than that of $P$. fluorescens strain A506 (Fig. 2A and B). Wetting increased hypanthial populations of bacteria (Fig. 2C and D). This was most notable for populations of $P$. agglomerans, which changed from barely detectable to a size greater than $3 \log$ CFU per flower in 1997 or between 1.5 and $3.0 \log$ CFU per flower in 1998. Hypanthial populations of $P$. agglomerans were generally 2 or $3 \log$ units larger than those of $P$. fluorescens strain A506.

On nonenclosed trees, population size of the antagonist representing each treatment was determined only for flower stigmas prior to wetting (Fig. 3A). Stigmatic populations were similar in size to those on enclosed trees; all exceeded $6 \log$ CFU per flower, and values were slightly higher in 1997 as compared to 1998 . With one exception, the population of strain A506 was statistically smaller than that of $P$. agglomerans.

Flowers of all treatments sampled from enclosed trees were evaluated for population size of the pathogen, E. amylovora strain Ea153, on the stigma and hypanthium before and after wetting (Fig. 4). Populations on stigmas of nontreated control flowers ranged from 5.4 to $6.3 \mathrm{log}$ CFU per flower (Fig. 4A and B). In the hypanthium of control flowers, the population of E. amylovora was $0.25 \log$ CFU per flower prior to wetting, and after wetting, it increased to 2.0 and $3.3 \log \mathrm{CFU}$ per flower in 1997 and 1998, respectively (Fig. $4 \mathrm{C}$ and $\mathrm{D})$. The pathogen populations on flowers pretreated with different preparations of strain E325 never differed statistically from each other on both stigmas and hypanthia, and mean values for these treatments always ranked lower than those of treatments with the standard antagonis- tic strains. On stigmas, a statistical difference between treatments with E325 and the standard antagonists was shown in 1997, but not in 1998 (Fig. 4A and B). After wetting, pathogen populations in the hypanthium of flowers treated with E325 were always statistically lower than those of nontreated control flowers (Fig. 4C and D). This was true for a standard antagonist only in 1998.

Population size of E. amylovora on nonenclosed trees was determined only for stigmas prior to wetting (Fig. 3B). Relative differences among treatments were similar to those for stigmas of enclosed trees (Fig. $4 \mathrm{~A}$ and B). Treatments with strain E325 resulted in statistically smaller populations of E. amylovora as compared to other treatments, but no difference between standard antagonists and the control was shown. The stigmatic populations of $E$. amylovora on nontreated control flowers
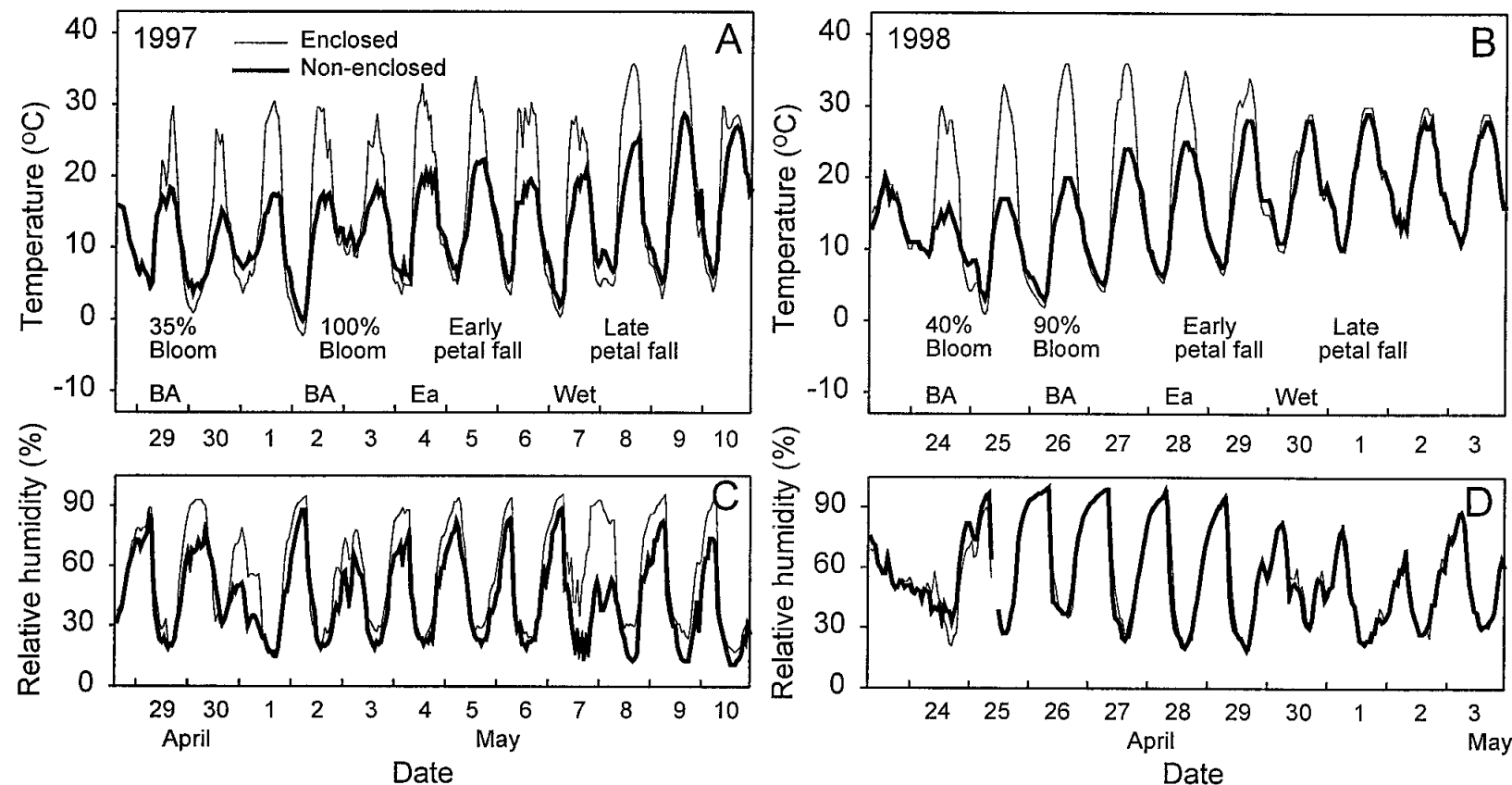

Fig. 1. Hourly temperature and relative humidity in A and C, 1997, and B and D, 1998, surrounding enclosed and nonenclosed apple trees. 'Jonagold' was used in 1997 and 'Gala' in 1998. Bloom stage and application dates for bacterial antagonists (BA), Erwinia amylovora (Ea), and artificial wetting (Wet) are indicated.

Table 1. Dispersal of Pseudomonas fluorescens strain A506 and Pantoea agglomerans strain C9-1 on enclosed and nonenclosed apple trees, as indicated by their frequency and population size on untreated control blossoms and blossoms treated with other antagonistic strains ${ }^{\mathrm{a}}$

\begin{tabular}{|c|c|c|c|c|c|c|c|c|c|c|c|}
\hline \multirow[b]{2}{*}{ Environment $^{\mathrm{d}}$} & \multirow{2}{*}{$\begin{array}{c}\text { Strain } \\
\text { detected }\end{array}$} & \multicolumn{5}{|c|}{ Frequency by treatment $(\%)^{b}$} & \multicolumn{5}{|c|}{ Log CFU by treatment ${ }^{c}$} \\
\hline & & Control & A506 & C9-1 & $\mathbf{E 3 2 5}$ & E325(FD) & Control & A506 & C9-1 & E325 & E325(FD) \\
\hline Enclosed & A506 & 40 & 100 & 5 & $10 * * *$ & $35^{*}$ & $3.7 \pm 1.0$ & $7.3 \pm 0.6$ & $5.0 \pm 0.0$ & $2.7 \pm 0.9$ & $4.2 \pm 1.5$ \\
\hline Nonenclosed & A506 & 70 & 100 & 20 & 65 & 75 & $5.0 \pm 0.6$ & $6.6 \pm 0.8$ & $4.9 \pm 0.5$ & $4.0 \pm 1.2$ & $3.1 \pm 1.0$ \\
\hline Enclosed & C9-1 & $15 * * *$ & 0 & 95 & $0 * * *$ & $0 * *$ & $5.5 \pm 1.7$ & 0 & $7.4 \pm 0.1$ & 0 & 0 \\
\hline Nonenclosed & C9-1 & 95 & 0 & 100 & 50 & 35 & $5.8 \pm 1.3$ & 0 & $7.3 \pm 0.4$ & $4.6 \pm 1.3$ & $3.4 \pm 1.4$ \\
\hline
\end{tabular}

a Data are from 'Jonagold' trees in 1997. Each treatment, involving fresh cultures of strain A506, C9-1, or E325 (P. agglomerans) or a freeze-dried (FD) culture of strain E325, was applied at 35\% and near 100\% bloom to one group of flower clusters on each of 10 enclosed trees and 10 nonenclosed trees. This was followed 3 days later by inoculation with Erwinia amylovora and 5 days later by sampling of 20 flowers per treatment to estimate bacterial populations.

${ }^{\mathrm{b}}$ Frequency is the percentage of flowers with detectable stigmatic populations of strain A506 or strain C9-1. Asterisks indicate a significant difference between enclosed and nonenclosed trees based on Fisher's two-sided exact test at $P<0.05(*), P<0.01$ (**), or $P<0.001$ (***).

${ }^{c}$ Only flowers with detectable bacteria were used to calculate mean population size expressed as log CFU per flower and the standard error.

${ }^{\mathrm{d}}$ Single trees were enclosed or not enclosed with polyethylene plastic to minimize bacterial dispersal by honeybees. 
prior to wetting were notably larger on enclosed trees than on nonenclosed trees. For enclosed trees, the 1997 and 1998 populations were $5.5 \pm 0.6$ (standard error) and $6.3 \pm 0.5 \log$ CFU per flower, respectively; for nonenclosed trees, they were 3.5 \pm 0.6 and $4.6 \pm 0.7 \log$ CFU per flower, respectively.

The comparison of biocontrol treatments based on disease expression was similar to that based on population size of E. amylovora. Treatments with fresh and lyophilized preparations of strain E325 resulted in similar mean disease incidences that always ranked lower than those for all other treatments (Fig. 5). In both years, the range and statistical separation of mean values was greater for enclosed trees than for nonenclosed trees. Disease data for nonpollinated enclosed trees in 1997 were omitted from the analysis after it was discovered that noninfected flower clusters aborted on these trees but infected clusters generally remained attached. In 1997, treatments involving strains of $P$. agglomerans resulted in a statistically lower disease incidence compared with the control, but no such difference was indicated for nonenclosed trees. On enclosed trees in 1998, there was a clear statistical separation between treatments with E325 and those with the standard antagonists and between the standards and the control. For the nonenclosed trees, only the E325 treatments were statistically different from
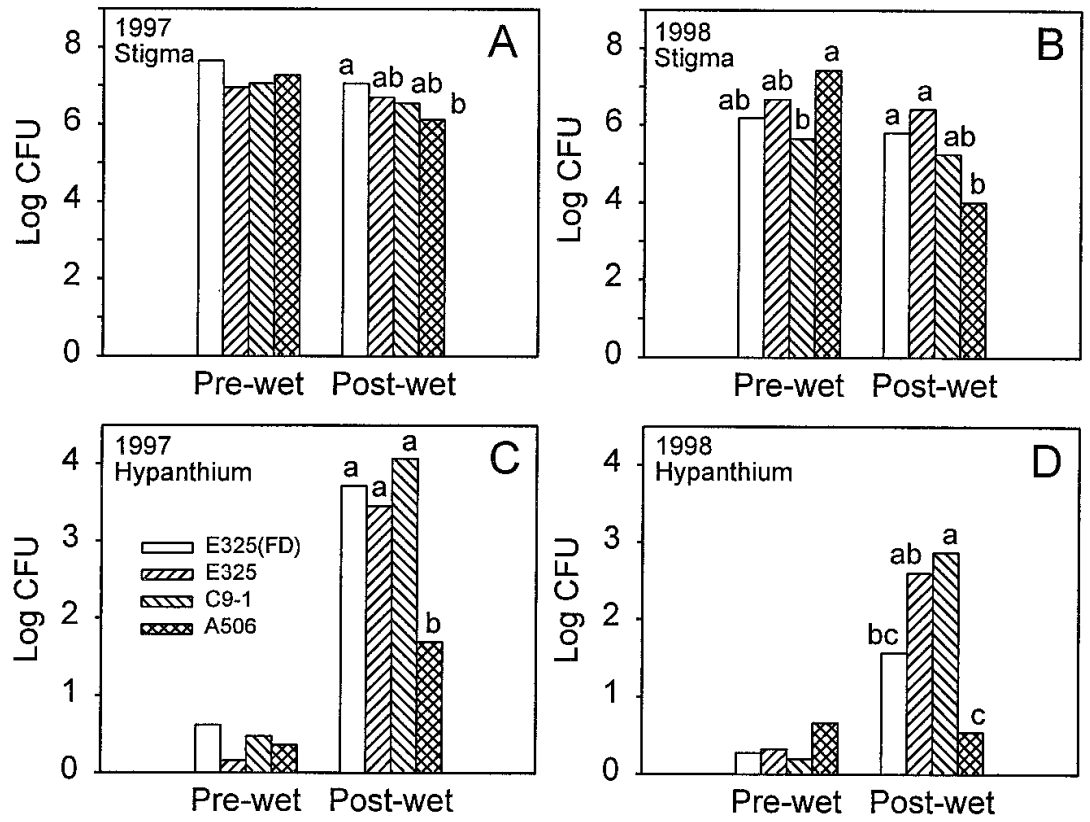

Fig. 2. Size of antagonist populations on $\mathbf{A}$ and $\mathbf{B}$, the stigma, and $\mathbf{C}$ and $\mathbf{D}$, the hypanthium, of enclosed trees of 'Jonagold' apple in 1997 and 'Gala' apple in 1998 before and after wetting. Treatments were Pantoea agglomerans strain E325, P. agglomerans strain C9-1, and Pseudomonas fluorescens strain A506 prepared from fresh cultures, and strain E325 also prepared from a freeze-dried (FD) culture. The second of two antagonist applications was followed 2 days later by inoculation with Erwinia amylovora and 4 or 5 days later by a wetting period of 8 or $11 \mathrm{~h}$. Flowers were sampled immediately prior to wetting and 2 days after wetting to determine bacterial populations. Each bar represents mean of $\log$ CFU per flower. Within each group of bars representing pre- or post-wetting results, means with unlike letters were different according to the least significant difference test $(P \leq$ $0.05)$. incidence values among treatments. The presence of endemic microorganisms did not appear to affect results on nonenclosed trees, since the frequency and size of such populations were negligible.

The enclosures did not totally prevent bees from coming into contact with the trees, since bees were occasionally discovered inside. Use of the tree enclosures was also labor intensive and would not be feasible in many research programs or commercial-scale trials. The study, however, draws attention to an issue that deserves consideration when interpreting results of tests with different microbial agents known to spread within an orchard (16). Alternatively, trials could be performed in relatively large orchard blocks with numerous buffer trees to reduce cross-contamination between treatments, and microbial populations on flowers could be monitored to avoid misinterpreting results.

Although the enclosures were also used to increase the rate of bacterial multiplication by increasing daytime temperatures, it was not evident that the antagonists or pathogen multiplied faster under these conditions. Populations of E. amylovora on control flowers were larger on enclosed trees than on nonenclosed trees, but this
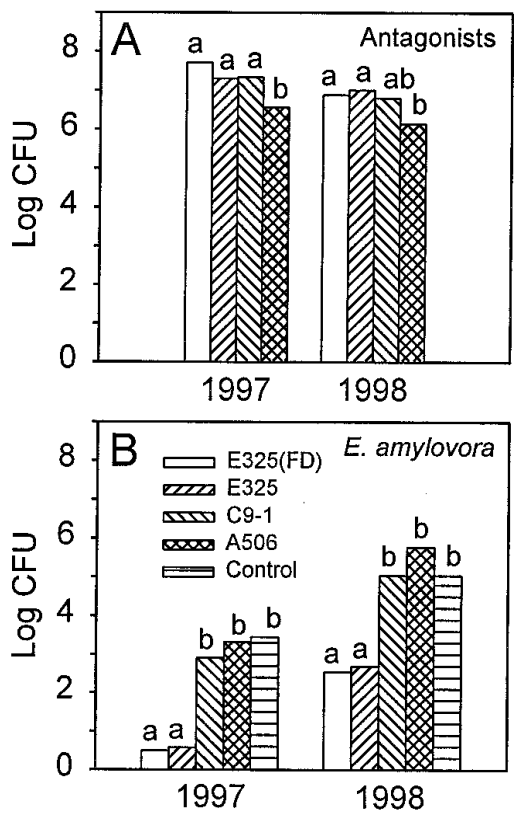

Fig. 3. Size of populations of A, antagonists, and $\mathbf{B}$, Erwinia amylovora, prior to wetting on stigmas of nonenclosed trees of 'Jonagold' apple in 1997 and 'Gala' apple in 1998. Treatments were Pantoea agglomerans strain E325, P. agglomerans strain C9-1, and Pseudomonas fluorescens strain A506 prepared from fresh cultures, and strain E325 also prepared from a freeze-dried (FD) culture. Antagonists were applied prior to inoculation with E. amylovora. Each bar represents mean of log CFU per flower. Within each group of bars representing 1997 or 1998 results, means with unlike letters were different according to the least significant difference test $(P \leq 0.05)$. 
may represent a difference in pathogen suppression caused by the spread of antagonists. Temperature may not have been a limiting factor in 1997 , and probably was not in 1998, when higher than usual temperatures favored fire blight. It is also possible that bacterial populations increased at different rates under the two sets of conditions, but flowers were sampled after all populations had reached maximum size.

The inoculation of flower stigmas with E. amylovora and subsequent artificial wetting of trees effectively simulated the natural progression of events leading to disease development in the field (24). The addition of moisture resulted in a sudden increase of pathogen populations in the hypanthium, where infection is generally initiated. This procedure may be especially useful for fire blight testing in arid regions where moisture in the form of rain or heavy dew is frequently absent during critical periods when pathogen populations on flower stigmas are high. Wetting may be administered for a much shorter period (between 1 and $4 \mathrm{~h}$ ) than the 8 or $11 \mathrm{~h}$ used in the present field experiment, based on recent laboratory studies with detached crabapple flowers (21).

All antagonists in the experiment colonized the flower stigmas and multiplied over a 48- or 72-h period to a size approaching or exceeding $6 \log \mathrm{CFU}$ per flower, as previously reported for these bacterial strains $(17,30)$. The stigmatic populations generally continued to be near maximum size beyond the wetting period. By contrast, hypanthial populations of the antagonists were barely detectable before wetting, but water caused a significant increase in the population of $P$. agglomerans strains C9-1 and E325. Hypanthial populations of $P$. fluorescens strain A506 remained relatively small after wetting. The difference in the capacity of strains C9-1 and A506 to survive and multiply in the hypanthium was demonstrated earlier in the laboratory with detached flowers of crabapple (17). Strain A506 is less adapted than strains of $P$. agglomerans to the highsugar, low-water-potential conditions that exist in the hypanthium, the site of nectar secretion and deposition. This explanation is supported by studies in which bacteria and yeast strains were incubated in artificial nectar of varying sugar concentration and composition (18).

Although populations of antagonist strains on the stigma were generally of comparable size, they consistently differed in their capacity to suppress E. amylovora on this flower tissue. These results agree with a previous study in which a larger number of antagonist strains were applied to different pomaceous flowers (17). If competition for nutrients and preemptive exclusion are the primary modes of antagonism, strains may differ in their capacity to compete for specific sites or nutrients that delimit the epiphytic niche of the
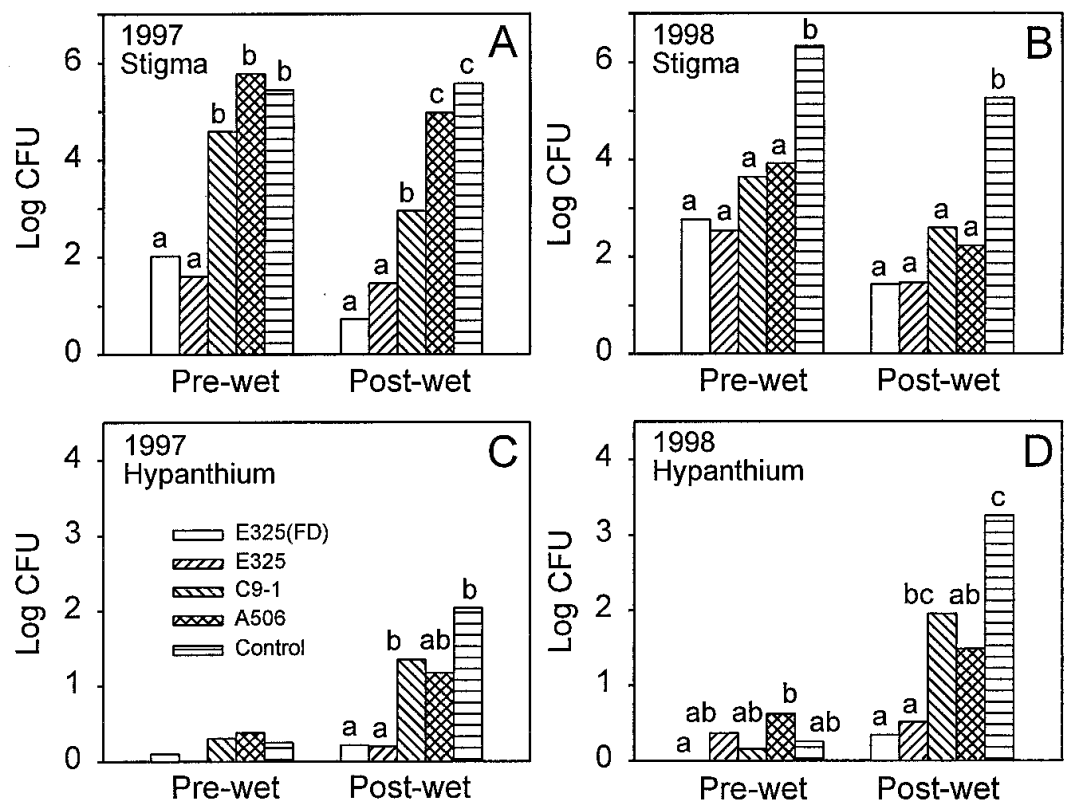

Fig. 4. Size of populations of Erwinia amylovora on $\mathbf{A}$ and $\mathbf{B}$, stigma, and $\mathbf{C}$ and $\mathbf{D}$, hypanthium, of enclosed trees of 'Jonagold' apple in 1997 and 'Gala' apple in 1998 in response to treatment with antagonists. Treatments were Pantoea agglomerans strain E325, P. agglomerans strain C9-1, and Pseudomonas fluorescens strain A506 prepared from fresh cultures, and strain E325 also prepared from a freeze-dried (FD) culture. The second of two antagonist applications was followed 2 days later by inoculation with E. amylovora and 4 or 5 days later by a wetting period of 8 or $11 \mathrm{~h}$. Flowers were sampled immediately prior to wetting and 2 days after wetting to determine bacterial populations. Each bar represents mean of $\log \mathrm{CFU}$ per flower. Within each group of bars representing preor post-wetting results, means with unlike letters were different according to the least significant difference test $(P \leq 0.05)$.

pathogen. Alternatively, other mechanisms may be involved. For instance, the effectiveness of strains of $P$. agglomerans has been linked with the production of antibiotics $(4,8,27)$. Strain C9-1 produces two antibiotics, herbicolins $\mathrm{O}$ and $\mathrm{I}$, that are inhibitory to E. amylovora (7). Strain E325 produced substances inhibitory to E. amylovora on certain agar media (P. L. Pusey, unpublished), but this has not been consistently observed in repeated trials and it is undetermined whether such inhibition occurs on flower tissues. In general, relative differences among treatments based on population size of E. amylovora were similar for the stigma and the hypanthium (after wetting). It is uncertain whether antagonism occurred in the hypanthium or whether pathogen populations there merely reflected bacterial movement from the stigma during the wetting period.

The higher incidence of disease resulting from antagonist treatments on nonenclosed trees as compared to enclosed trees in 1997 is not understood. One possible explanation is that cross-contamination of treatments led to an interaction between antagonist strains. As an example of how antagonist interactions could negatively affect biocontrol mechanisms, Stockwell et
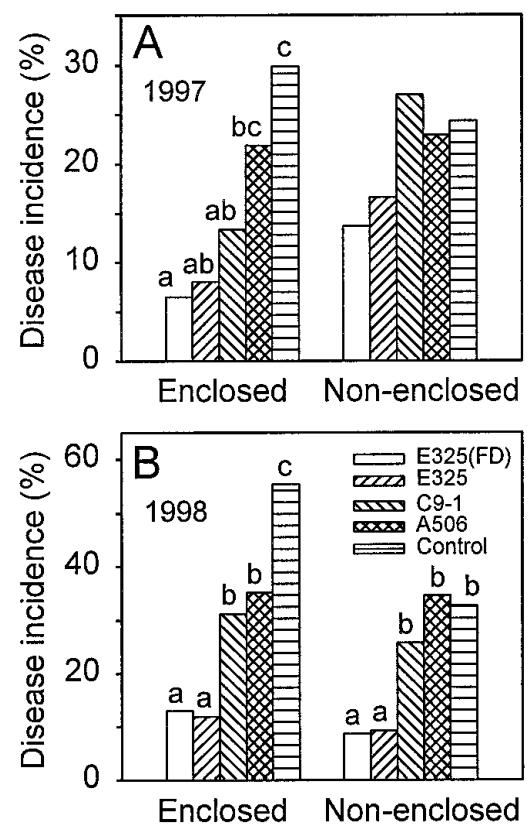

Fig. 5. Incidence of blossom clusters infected with Erwinia amylovora on enclosed or nonenclosed trees of A, 'Jonagold' apple in 1997, and B, 'Gala' apple in 1998, following treatment with antagonists. Treatments were Pantoea agglomerans strain E325, P. agglomerans strain C9-1, and Pseudomonas fluorescens strain A506 prepared from fresh cultures, and strain E325 also prepared from a freeze-dried (FD) culture. Within each group of bars representing results of enclosed or nonenclosed trees, means with unlike letters were different according to the least significant difference test $(P \leq 0.05)$. 
al. (23) reported that pathogen-inhibiting antibiotics produced by one strain of $P$. agglomerans were detoxified by an extracellular metalloprotease produced by $P$. fluorescens strain A506.

The comparative effectiveness of antagonistic strains based on floral populations of E. amylovora and blossom blight incidence was consistent. Standard strains A506 and C9-1 were generally similar, but C9-1 was sometimes slightly more effective. Johnson and Stockwell (8) indicated that in multiple field trials, the reduction in disease incidence with A506 was between 50 and $70 \%$, and with C9-1 it was between 50 and $80 \%$. Reductions caused by strain A506 in the present trials were below these ranges but higher than reductions reported for A506 in other studies $(15,27,28)$. Possible reasons for the wide range of results include differences in experimental conditions and methods. Treatments with $P$. agglomerans strain E325 were always more effective than the standard treatments in suppressing the pathogen according to a ranking of mean values, but differences were not always statistically significant. The field data confirm results of earlier tests in which strain E325 was compared with other microbial antagonists based only on the suppression of E. amylovora on flower stigmas $(17,19)$. The lyophilized preparation of $\mathrm{E} 325$, even after being stored for 1 year at $-20^{\circ} \mathrm{C}$, was just as effective as the fresh-culture preparation. Currently, this organism is of commercial interest; however, many large-scale trials under various conditions will be necessary before its potential value for fire blight management can be fully assessed.

\section{ACKNOWLEDGMENTS}

This research was supported in part by funds from the Washington Tree Fruit Research Commission. I thank Janet Duffy, Brenda Steady, Barbara Blaisdell, and Dwayne Visser for their technical assistance.

\section{LITERATURE CITED}

1. Aldwinckle, H. S., and Beer, S. V. 1979. Fire blight and its control. Hortic. Rev. 1:423-474.

2. Ark, P. A., and Hunt, M. L. 1941. Saprophytes antagonistic to phytopathogenic and other microorganisms. Science 93:354-355.

3. Beer, S. V., and Rundle, J. R. 1983. Suppres- sion of Erwinia amylovora by Erwinia herbicola in immature pear fruits. (Abstr.) Phytopathology 73:1346.

4. Epton, H. A. S., Wilson, M., Nicholson, S. L., and Sigee, D. C. 1994. Biological control of Erwinia amylovora with Erwinia herbicola. Pages 335-352 in: Ecology of Plant Pathogens. J. P. Blakeman and B. Williamson, eds. CAB International, Wallingford, UK.

5. Isenbeck, M., and Schulz, F. A. 1985. Biological control of fire blight (Erwinia amylovora [Burr.] Winslow et al.) on ornamentals: I. Control of the pathogen by antagonistic bacteria. Phytopathol. Z. 113:324-333.

6. Ishimaru, C., and Klos, E. J. 1984. New medium for detecting Erwinia amylovora and its use in epidemiological studies. Phytopathology 74:1342-1345.

7. Ishimaru, C. A., Klos, E. J., and Brubaker, R. R. 1988. Multiple antibiotic production by $\mathrm{Er}$ winia herbicola. Phytopathology 78:746-750.

8. Johnson, K. B., and Stockwell, V. O. 1998. Management of fire blight: A case study in microbial ecology. Annu. Rev. Phytopathol. 36:227-248.

9. Johnson, K. B., Stockwell, V. O., Burgett, D. M., Sugar, D., and Loper, J. E. 1993. Dispersal of Erwinia amylovora and Pseudomonas fluorescens by honey bees from hives to apple and pear blossoms. Phytopathology 83:478484.

10. Johnson, K. B., Stockwell, V. O., McLaughlin, R. J., Sugar, D., Loper, J. E., and Roberts, R. G. 1993. Effect of antagonistic bacteria on establishment of honey bee-dispersed Erwinia amylovora in pear blossoms and on fire blight control. Phytopathology 83:995-1002.

11. King, E. O., Ward, M. K., and Raney, D. E. 1954. Two simple media for the demonstration of pyocyanin and fluorescin. J. Lab. Clin. Med. 44:301-307.

12. Lindow, S. E., McGourty, G., and Elkins, R. 1996. Interactions of antibiotics with Pseudomonas fluorescens strain A506 in the control of fire blight and frost injury to pear. Phytopathology 86:841-848.

13. Loper, J. E., Henkels, M. D., Roberts, R. G., Grove, G. G., Willet, M. J., and Smith, T. J. 1991. Evaluation of streptomycin, oxytetracycline, and copper resistance of Erwinia amylovora isolated from pear orchards in Washington State. Plant Dis. 75:287-290.

14. McManus, P. S., and Jones, A. L. 1994. Epidemiology and genetic analysis of streptomycin-resistant Erwinia amylovora from Michigan and evaluation of oxytetracycline for control. Phytopathology 84:627-633.

15. Momol, M. T., Norelli, J. L., and Aldwinckle, H. S. 1998. Evaluation of biological control agents, systemic acquired resistance inducers and bactericides for the control of fire blight on apple blossom. Acta Hortic. 489:553-557.

16. Nuclo, R. L., Johnson, K. B., Stockwell, V.
O., and Sugar, D. 1998. Secondary colonization of pear blossoms by two bacterial antagonists of the fire blight pathogen. Plant Dis. 82:661-668.

17. Pusey, P. L. 1997. Crab apple blossoms as a model for research on biological control of fire blight. Phytopathology 87:1096-1102.

18. Pusey, P. L. 1999. Effect of nectar on microbial antagonists evaluated for use in control of fire blight of pome fruits. Phytopathology 89:39-46.

19. Pusey, P. L. 1999. Control of fire blight on pome fruit trees with Erwinia herbicola. United States Patent No. 5,919,446.

20. Pusey, P. L. 1999. Laboratory and field trials with selected microorganisms as biocontrol agents for fire blight. Acta Hortic. 489:655661.

21. Pusey, P. L. 2000. The role of water in epiphytic colonization and infection of pomaceous flowers by Erwinia amylovora. Phytopathology 90:1352-1357.

22. Stockwell, V. O., Johnson, K. B., and Loper J. E. 1996. Compatibility of bacterial antagonists of Erwinia amylovora with antibiotics used to control fire blight. Phytopathology 86:834-840.

23. Stockwell, V. O., Johnson, K. B., and Loper, J. E. 1999. Ecological and mechanistic compatibility as criteria for antagonist mixtures for control of fire blight. (Abstr.) Phytopathology 89:S75.

24. Thomson, S. V. 1986. The role of the stigma in fire blight infections. Phytopathology 76:476-482.

25. Thomson, S. V., Hansen, D. R., Flint, K. M., and Vandenberg, J. D. 1992. Dissemination of bacteria antagonistic to Erwinia amylovora by honey bees. Plant Dis. 76:1052-1056.

26. Van der Zwet, T., and Keil, H. L. 1979. Fire blight: A bacterial disease of rosaceous plants. U.S. Dep. Agric., Sci. Educ. Admin., Agric. Handb. 510.

27. Vanneste, J. L. 1996. Honey bees and epiphytic bacteria to control fire blight, a bacterial disease of apple and pear. Biocontrol News Information 17:67N-78N.

28. Vanneste, J. L., and Yu, J. 1996. Biological control of fire blight using Erwinia herbicola Eh252 and Pseudomonas fluorescens A506 separately or in combination. Acta Hortic. 411:351-353.

29. Vanneste, J., Yu, J., Harper, G. E., and Perry, J. H. 1996. Plugs of immature pear fruit to assess the virulence of Erwinia amylovora and to study in the laboratory the interaction between biological control agents and the fire blight pathogen. Acta Hortic. 411:303-305.

30. Wilson, M., and Lindow, S. E. 1993. Interactions between the biological control agent Pseudomonas fluorescens A506 and Erwinia amylovora in pear blossoms. Phytopathology 83:117-123. 